\title{
Threshold Chloride Concentration of Stainless Steels in Simulated Concrete Pore Solution
}

\author{
Hailong Wang, Jiayan Ling, and Xiaoyan Sun \\ Department of Civil Engineering, Zhejiang University, Hangzhou 310058, China
}

\begin{abstract}
To evaluate whether stainless steel can replace carbon steel as rebar in reinforced concrete structures exposed to aggressive environment, the threshold chloride concentration of carbon steel, austenitic and duplex stainless steels were experimentally studied in this paper. The solutions with $\mathrm{pH}$ ranging from 9.5 to 13.6 were used herein to simulate the pore liquids in both alkaline and carbonated concretes. Potentiodynamic polarization and electrochemical impedance spectroscopy (EIS) tests were carried out in the solutions with chloride concentration ranging from 0 to $5.0 \mathrm{M}$ and at a temperature around $25^{\circ} \mathrm{C}$. The activation of pitting corrosion was determined when corrosion current increased and polarization resistance decreased significantly. The test results show that the $\mathrm{pH}$ value has a great effect on the evolution of the film resistance, and stainless steels have much higher corrosion resistance than carbon steel subjected to chloride environments.
\end{abstract}

\section{INTRODUCTION}

Reinforced concrete $(\mathrm{RC})$ structure is one of the most useful and economical structures in the world. However, the deficiency of durability becomes a weakness of conventional RC structure, especially in the severe corrosion conditions such as ocean, de-icing, or other chloride-contaminated environment. On the surface of steel, there is a protective, thin oxide layer formed in high alkaline media (Gancedo, Alonso, Andrade, \& Gracia, 1989), which can be broken by chloride ions at a certain concentration. Fresh concrete can provide a high alkaline environment in the concrete pores, benefitting the form of this passive film. However, when the concrete is completely carbonated, the $\mathrm{pH}$ value of pore solution will drop to 9.5 or so, and the film of steel will not be stable any longer and starts to dissolve, leading to steel activation.

To resolve the corrosion problem, cathodic protection and the use of stainless steel reinforcements seem to be the most reliable solutions to guarantee the durability of RC structure existing in the aggressive environments (Castro-Borges et al., 2002; Knudsen, Jensen, Klinghoffer, \& Skovsgaard, 1998). Using stainless steels can essentially improve the corrosion resistance of embedded bars, because the alloy elements of chromium, nickel, and molybdenum can form a more stable oxide layer protecting the metallic matrix beneath the film away from chloride corrosion. However, the increasing cost during the construction phase limits its use (Fajardo, Bastidas, Criado, Romero, \& Bastidas, 2011), although it is a more economical alternative assessing from the life cycle cost.
Stainless steel is more passive but susceptible to localized corrosion in the presence of chloride ions (Freire, Carmezim, Ferreira, \& Montemor, 2011). This is why most of the studies were conducted to figure out the corrosion behavior of stainless steel bars embedded in concrete or submerged in simulated pore solution. The first study on the corrosion behaviors of stainless steel reinforcements in chloridecontaminated concrete were carried out in the 1970s. And after 10 years of exposure, the stainless steel had not corroded, even in the highest chloride content (Bertolini, Bolzoni, Pastore, \& Pedeferri, 1996).

Recently, numerous studies were explored to discuss the stainless steel at many aspects. Freire et al. (2011) focused on the corrosion behavior of AISI304 in simulated pore solutions with different $\mathrm{pH}$ and chloride concentration. The results showed that the $\mathrm{pH}$ played an important role in the evolution of the film resistance and charge transfer process. Bertolini et al. (1996) studied the influence of carbonation on the critical chloride concentration. They found that higher temperature would decrease the critical value; however, the results are opposite in the solutions with high carbonate/bicarbonate concentration which showed an inhibitive effect to the corrosion. Furthermore, Kouriil, Novák, and Bojko (2010) figured out the relationship between the superficial state of the steel and the corrosion resistance, which confirmed that the scaled surface had lower resistance even for the most alloyed stainless steels.

As discussed above, most of the researches focused on the difference of corrosion resistance between stainless steels, but few of them considered the exact 
value of threshold chloride concentrations. The main objective of this study is to figure out the critical chloride value, so that the stainless steel bars can be used in an appropriate situation. Two stainless steels (austenitic type 316 and duplex type 2205) and one carbon steel (HRB400) have been electrochemically characterized in simulated pore solutions to accomplish this aim.

\section{EXPERIMENTAL PROGRAMME}

Cylinder samples with a length of $1.5 \mathrm{~mm}$ were obtained from each kind of steel reinforcement. The side and one cross-section of the sample were covered by epoxy, and another cross-section was polished as working electrode. A three-electrode system was set up when other two electrodes were incorporated and acted as counter electrode (Platinum electrode) and reference electrode, respectively. The potential of working electrode was obtained referring to the saturated calomel electrodes (SCE). The chemical compositions of the stainless steels with the diameter of $12 \mathrm{~mm}$ are shown in Table 1.

Table 1. Chemical composition of steels.

\begin{tabular}{lcccccccc}
\hline $\begin{array}{l}\text { Compo- } \\
\text { sition }\end{array}$ & C & Mn & P & S & Si & Cr & Ni & Mo \\
\hline HRB400 & $\leq 0.25$ & $\leq 1.6$ & $\leq 0.045$ & $\leq 0.045$ & $\leq 0.8$ & - & - & - \\
316 & $\leq 0.08$ & $\leq 2.0$ & $\leq 0.035$ & $\leq 0.03$ & $\leq 1.0$ & $16-$ & $10-$ & $2-3$ \\
& & & & & & 18.5 & 14 & \\
2205 & $\leq 0.03$ & $\leq 2.0$ & $\leq 0.030$ & $\leq 0.02$ & $\leq 1.0$ & $22-$ & $4.5-$ & $3-$ \\
& & & & & & 23 & 6.5 & 3.5 \\
\hline
\end{tabular}

Three $\mathrm{pH}$ values were selected to simulate different status of concrete pore solutions:

(i) $0.1 \mathrm{M} \mathrm{Na}_{2} \mathrm{CO}_{3}$ and $0.2 \mathrm{M} \mathrm{NaHCO}_{3}$ with a $\mathrm{pH}$ value of 9.5 , simulating completely carbonated concrete;

(ii) $0.01 \mathrm{M} \mathrm{Ca}(\mathrm{OH})_{2}$ and $0.03 \mathrm{M} \mathrm{NaOH}$ with a $\mathrm{pH}$ value of 12.6, simulating fresh concrete;

(iii) $0.01 \mathrm{M} \mathrm{Ca}(\mathrm{OH})_{2}$ and $0.4 \mathrm{M} \mathrm{NaOH}$ with a $\mathrm{pH}$ value of 13.6 , simulating the concrete with a high alkali content.

All solutions were prepared with deionized water. Chloride ions would be added into the solutions with concentrations of $0-5.0 \mathrm{M}$ after the samples were submerged in solutions about 5 days; at this moment, the passive film of samples had formed completely.

An electrochemical test system, named Gamry Reference 600, was used to conduct the electrochemical experiments. As two important electrochemical parameters, the corrosion current and the polarization resistance, indicating the initiation of corrosion, can be figured out through potentiodynamic test and EIS test, respectively. Both tests were carried out at a room temperature around $25^{\circ} \mathrm{C}$.

The potentiodynamic test began at a potential of $-70 \mathrm{mV}$ (vs. Eoc) and stopped at $+70 \mathrm{mV}$ (vs. Eoc). The scan rate was $0.15 \mathrm{mV} / \mathrm{s}$. The EIS test was carried out in the frequencies from $10^{6}$ to $10^{-3} \mathrm{~Hz}$. The former test was performed per 10-12 $\mathrm{h}$ before the addition of chloride ions. After the addition of chloride ions, both tests were carried out once per day.

The polarization curves were fitted by the software of Gamry Echem Analyst, and the EIS curves were fitted by Zsimp Win.

\section{RESULTS AND DISCUSSIONS}

The impedance data of EIS had been modeled using the equivalent circuits, as illustrated in Figure 1. Both capacitors in the figure had been modeled as constant phase element (CPE), which represented the double layer formed on the material surface. A CPE unit was often used instead of an ideal capacitor to account for a non-ideal capacitive response from the steel/electrolyte interface. The equivalent circuit had also been used by other authors to simulate the chemical behavior of passive layer in chloride-contaminated solutions.

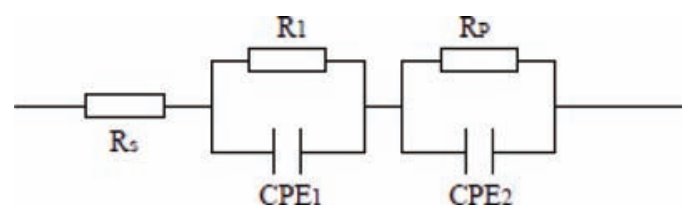

Figure 1. Equivalent circuit for EIS fitting.

The meanings of the circuit components are different. $R_{\mathrm{s}}$ represents the ohmic resistance of the electrolyte at high frequencies. The medium-frequency time constants $\left(R_{1}\right.$ and $\left.\mathrm{CPE}_{1}\right)$ seem to be related with a redox reaction on the steel surface. At low frequency, the time constants $\left(R_{\mathrm{p}}\right.$ and $\left.\mathrm{CPE}_{2}\right)$ represent the charge transfer process, and $R_{\mathrm{p}}$ is considered as the polarization resistance. Furthermore, the $R_{\mathrm{p}}$ correspond with corrosion intensities $\left(i_{\text {corr }}\right)$ is similar to the $i_{\text {corr }}$ obtained from potentiodynamic test (Blanco, Bautista, \& Takenouti, 2006).

Figures 2 and 3 show the polarization resistance $\left(R_{\mathrm{p}}\right)$ and the corrosion current $\left(i_{\text {corr }}\right)$ of austenitic stainless steel 316 subjected to various chloride concentration solutions. It can be seen that after immersion the value of $i_{\text {corr }}$ dropped slightly, while the corrosion initiated, the $i_{\text {corr }}$ increased significantly, just as the case of chloride content increasing from 1.0 to $3.0 \mathrm{M}$ at the $\mathrm{pH}$ value of 12.6, as shown in Figure 3. At the same time, the value of $R_{\mathrm{p}}$ decreased suddenly. It can 
be concluded that the critical chloride concentration at $\mathrm{pH} 12.6$ was in the range of 1.0-3.0M. However, there were no obvious changes at the $\mathrm{pH}$ values of 9.5 and 13.6; therefore, the critical value in these two conditions can be deemed as more than $5.0 \mathrm{M}$. Moreover, the value of $R_{\mathrm{p}}$ maintained in the magnitude from $10^{5}$ to $10^{6} \mathrm{ohm}$, and the value of $i_{\text {corr }}$ maintained in the magnitude from $10^{-8}$ to $10^{-7} \mathrm{~A}$.

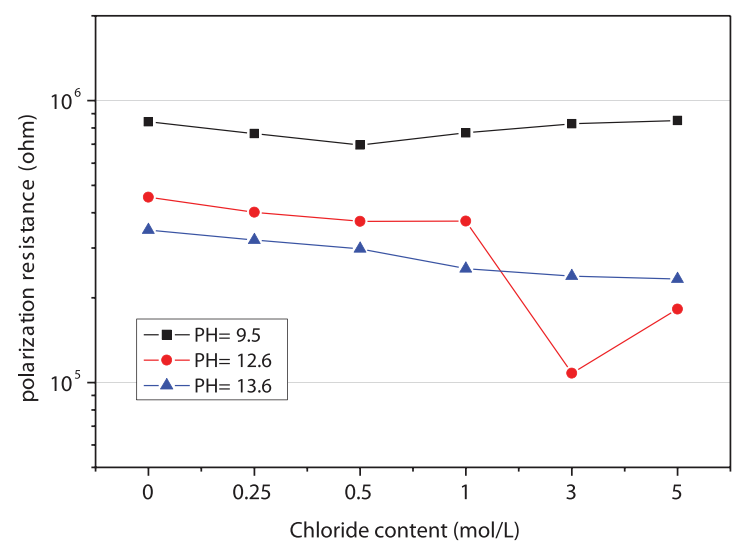

Figure 2. Influence of $\mathrm{pH}$ value and chloride contents on the value of $R_{\mathrm{p}}$ for austenitic stainless steel 316 .

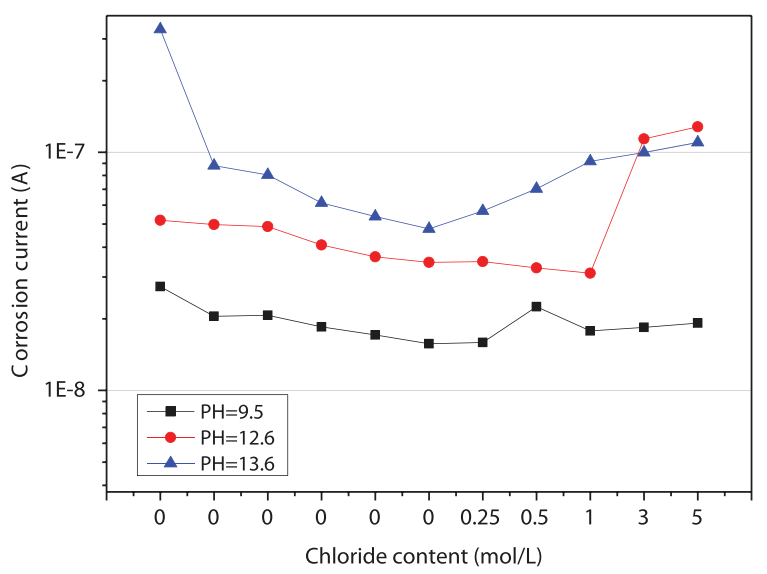

Figure 3. Influence of $\mathrm{pH}$ value and chloride contents on the value of $i_{\text {corr }}$ for austenitic stainless steel 316.

Figures 4 and 5 showed the value of $R_{\mathrm{p}}$ and $i_{\text {corr }}$ of duplex stainless steel 2205 subjected to various chloride concentration solutions. At $\mathrm{pH}$ 12.6, the value of $R_{\mathrm{p}}$ decreased at the first level of chloride content, while $i_{\text {corr }}$ increased a lot as well. Thereby, the critical chloride concentration for 2205 at this $\mathrm{pH}$ value ranges from 0 to $0.25 \mathrm{M}$. Similarly, at $\mathrm{pH} 9.5$, the critical chloride concentration lies in the range of $0.25-0.5 \mathrm{M}$. The results of polarization resistance at $\mathrm{pH} 13.6$ were not presented in Figure 4, for the reason that the curves were almost linear, which will result in great errors of fitting results. The original curves were displayed in Figure 6. No sharp reduction in the diameters of circular arcs means no pitting corrosion in the steel. It can also be found that the $R_{\mathrm{p}}$ of 2205 varied in the magnitude from $10^{4}$ to $10^{6} \mathrm{ohm}$, and the value of $i_{\text {corr }}$ stabilized around the magnitude of $10^{-7} \mathrm{~A}$.

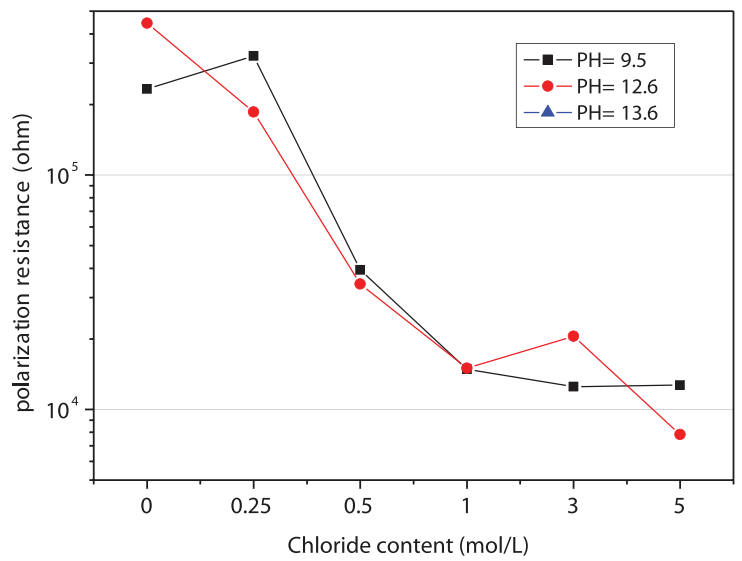

Figure 4. Influence of $\mathrm{pH}$ value and chloride contents on the value of $R_{\mathrm{p}}$ for duplex stainless steel 2205.

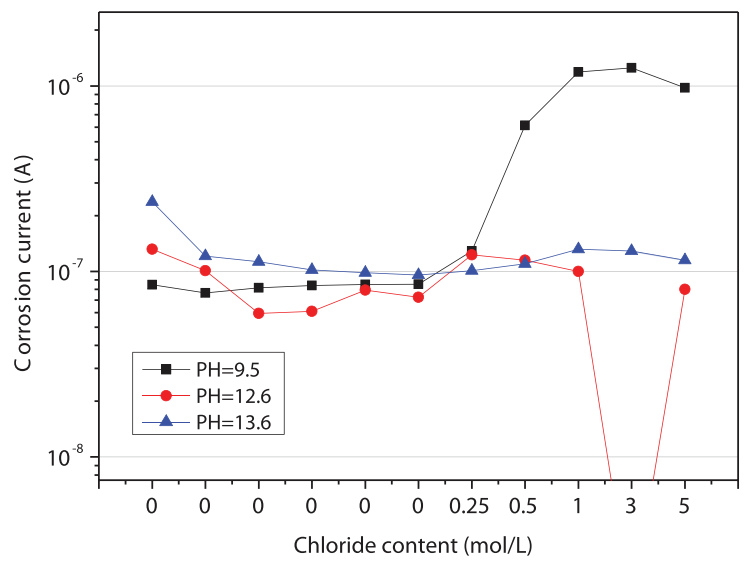

Figure 5. Influence of $\mathrm{pH}$ value and chloride contents on the value of $\boldsymbol{i}_{\text {corr }}$ for duplex stainless steel 2205.

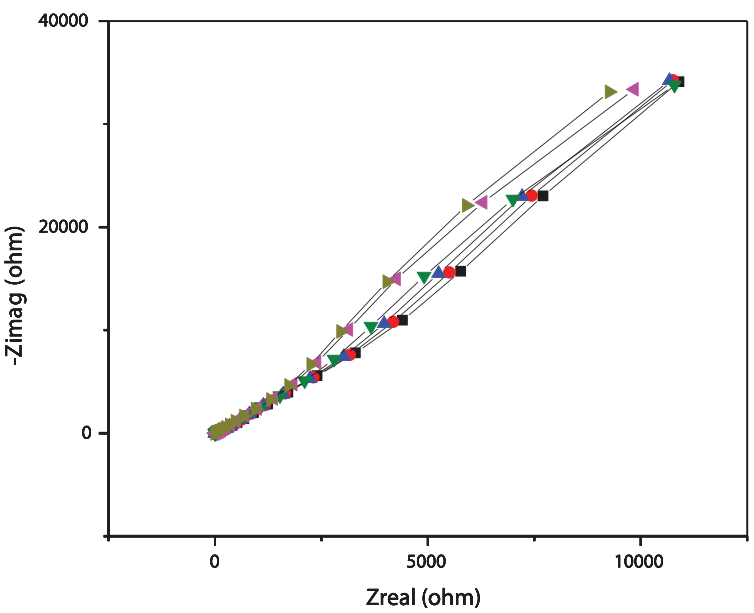

Figure 6. Nyquist chart in EIS test for duplex stainless steel 2205 at the $\mathrm{pH}$ value of 9.5 . 
The results of HRB400 were presented in Figures 7 and 8. The chloride content increased from 0.05 to $0.35 \mathrm{M}$ with an increment of $0.05 \mathrm{M}$. In the solutions of $\mathrm{pH} 12.6$ and 13.6 , the critical chloride concentrations were lower than $0.05 \mathrm{M}$, those was different with that at $\mathrm{pH}$ 9.5. At this $\mathrm{pH}$ value, the corrosion did not happened even the chloride content was up to $0.35 \mathrm{M}$. At the $\mathrm{pH}$ values of 12.6 and 13.6, the values of $R_{\mathrm{p}}$ were in the range of $10^{4}-10^{5} \mathrm{ohm}$, and $i_{\text {corr }}$ was around the value of $10^{-6} \mathrm{~A}$. Compared with the results of $R_{\mathrm{p}}$ and $i_{\text {corr }}$ of stainless steels, it is obvious that the carbon steel has the lowest corrosion resistance.

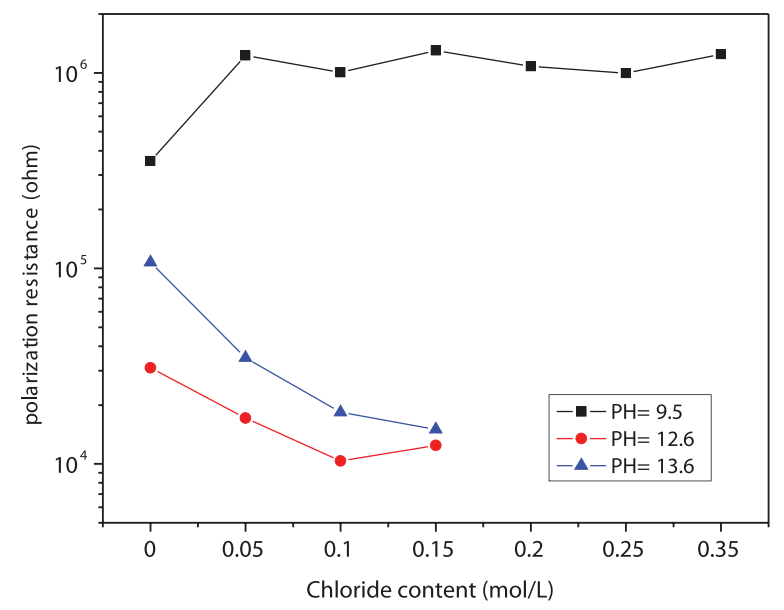

Figure 7. Influence of $\mathrm{pH}$ value and chloride content on the value of $R_{\mathrm{p}}$ for steel HRB400.

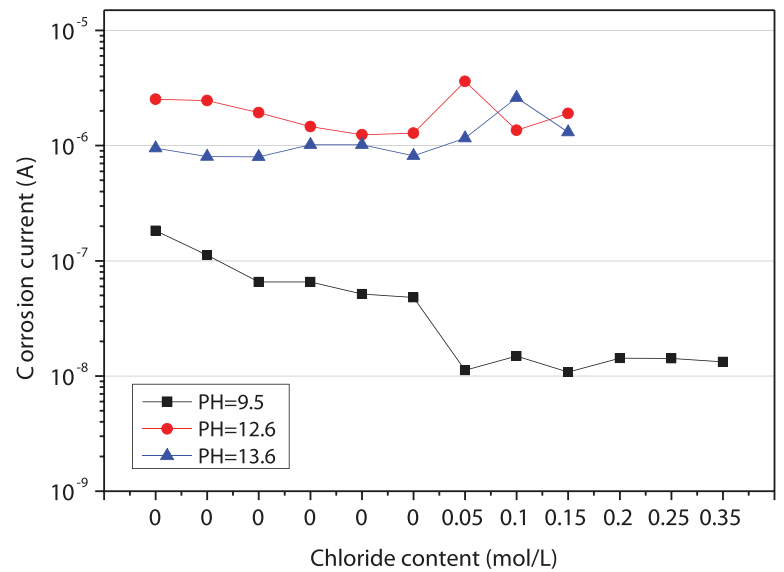

Figure 8. Influence of $\mathrm{pH}$ value and chloride content on the value of $i_{\text {corr }}$ for steel HRB400.

Concluded from the test results, the stainless steels behaved much better than the carbon steel, those can be employed in the RC structures under chloride environment. The chromium content in the 2205 is higher than 316 , which means the corrosion resistance of 2205 should be better theoretically. However, the austenitic stainless steel 316 performed better than the duplex stainless steel 2205 in this study. It can be seen that the nickel content is only half of the content of 316 , maybe it is the reason for the lower resistance of 2205 (Addari, Elsener, \& Rossi, 2008). More experiments about the contribution of alloy to the corrosion resistance of these two stainless steels are needed in the future.

The corrosion behaviors of three steels evidenced the influence of $\mathrm{pH}$ on the critical chloride concentration except for $\mathrm{pH}$ 9.5. With the increase of $\mathrm{pH}$ value, the film formed on the surface of steel became more stable, which enhanced the threshold chloride concentration as well. However, the critical values at $\mathrm{pH} 9.5$ were higher than those at $\mathrm{pH} 12.6$. Blanco et al. (2006) reported a similar result, but with no explanation. Bertolini et al. (1996) prepared two different solutions of $\mathrm{pH} 9$ as shown in Table 2, their experiment concluded that the high carbonate/ bicarbonate concentration had an inhibiting effect on the chloride corrosion. The results of $\mathrm{pH} 9.5$ in this paper also gave an evidence of the inhibiting effect.

Table 2. Solutions in Bertolini's study (Bertolini et al., 1996).

$\begin{array}{lc}\mathrm{pH}=9 & 0.015 \mathrm{M} \mathrm{NaHCO}_{3}+0.005 \mathrm{M} \mathrm{Na}_{2} \mathrm{CO}_{3} \\ \mathrm{pH}=9 & 0.3 \mathrm{M} \mathrm{NaHCO}_{3}+0.1 \mathrm{M} \mathrm{Na}_{2} \mathrm{CO}_{3}\end{array}$

\section{CONCLUSION}

The critical chloride concentrations of three different steel bars were experimentally studied in this paper. On the basis of the test results, the following conclusions can be reached:

- The value of critical chloride concentration is greatly affected by the $\mathrm{pH}$ value of simulated pore solution, and there is a positive correlation between these two parameters.

- High concentration of carbonate/bicarbonate did have an effect of inhibition. Further experiments should be conducted to figure out the regulation and the mechanisms.

- Nickel was an important composition of alloy for the corrosion resistance of stainless steels.

\section{ACKNOWLEDGMENTS}

The authors are grateful for the financial support received from the National High Technology Research and Development Program (863Program) of China (2015AA03A502) and the National Natural Science Foundation of China (51579220). 


\section{REFERENCES}

Addari, D., Elsener, B., \& Rossi, A. (2008). Electrochemistry and surface chemistry of stainless steels in alkaline media simulating concrete pore solutions. Electrochimica Acta, 53, 8078-8086.

Bertolini, L., Bolzoni, F., Pastore, T., \& Pedeferri, P. (1996). Behaviour of stainless steel in simulated concrete pore solution. British Corrosion Journal, 31(3), 218-222.

Blanco, G., Bautista, A., \& Takenouti, H. (2006). EIS study of passication of austenitic and duplex stainless steels reinforcements in simulated pore solutions. Cement \& Concrete Composites, 28, 212-219.

Castro-Borges, P., de Rincon, O. T., Moreno, E. I., Torres-Acosta, A. A., Martinez-Madrid, M., \& Knudsen, A. (2002). Performance of a 60-year old concrete pier with stainless steel reinforcement. Materials Performance, 41(10), 50-55.

Fajardo, S., Bastidas, D. M., Criado, M., Romero, M., \& Bastidas, J. M. (2011). Corrosion behaviour of a new low-nickel stainless steel in saturated calcium hydroxide solution. Construction and Building Materials, 25(11), 4190-4196.

Freire, L., Carmezim, M. J., Ferreira, M. G. S., \& Montemor, M. F. (2011). The electrochemical behaviour of stainless steel AISI 304 in alkaline solutions with different $\mathrm{pH}$ in the presence of chlorides. Electrochemica Acta, 56, 5280-5289.

Gancedo, J. R., Alonso, C., Andrade, C., \& Gracia, M. (1989). AES study of the passive layer formed on iron in saturated $\mathrm{Ca}(\mathrm{OH})_{2}$ solutions. Corrosion, 45(12), 976-982.

Knudsen, A., Jensen, F. M., Klinghoffer, O., \& Skovsgaard, T., (1998). Cost-effective enhancement of durability of concrete structures by intelligent use of stainless steel reinforcement. Conference on corrosion and rehabilitation of reinforced concrete structures, Florida.

Kouřil, M., Novák, P., \& Bojko, M. (2010). Threshold chloride concentration for stainless steels activation in concrete pore solutions. Cement and Concrete Research, 40, 431-436. 